\title{
Wear Characteristics of 22MnB5 Boron Steel under Friction Micro Pin-on-Disks Test
}

\section{Mohd Fairuz Rashid ${ }^{1}$, Hadzley Abu Bakar ${ }^{2 *}$, Abdul Aziz Adam ${ }^{3}$ Mohd Basri Ali $^{2}$, Faizal Abu Bakar ${ }^{4}$}

${ }^{1}$ Jabatan Keselamatan dan Kesihatan Pekerjaan Melaka, Aras 3 dan 4, Menara Persekutuan, Jalan Persekutuan, Hang Tuah Jaya, 75450 Ayer Keroh, Melaka, MALAYSIA

${ }^{2}$ Universiti Teknikal Malaysia Melaka, Fakulti Teknologi Kejuruteraan Mekanikal dan Pembuatan, Hang Tuah Jaya, 76100 Durian Tunggal, Melaka, MALAYSIA

${ }^{3}$ Kolej Kemahiran Tinggi MARA Masjid Tanah, KM 1, Persiaran, Kampung Paya Lebar, 78300 Masjid Tanah, Melaka, MALAYSIA

${ }^{4}$ HHA Associates Sdn. Bhd., PN 2370 \& 2371, Jalan Rancha-Rancha Lama, 87000 Wilyah Persekutuan Labuan, MALAYSIA

*Corresponding Author

DOI: https://doi.org/10.30880/jsmt.2021.01.01.003

Received 24 August 2021; Accepted 11 October 2021; Available online 15 December 2021

\begin{abstract}
MnB5 Boron Steel can be considered as emerged material for high strength and low weight application. This material potentially used in abrasive condition such as cutting tool or brake pad where high friction resistance applies. In this study, the wear characteristics of 22MnB5 was investigated under the frictional tests via micro pin-on-disk. 22MnB5 Boron Steel was prepared the form of round shape within the size of $2.6 \mathrm{~mm}$ thickness and $12 \mathrm{~mm}$ diameter by using laser cutting. 4 different samples were tested namely blank (sample A), self-hardening heat treatment (sample B), $60 \mathrm{HRC}$ hot stamped (sample C) and $70 \mathrm{HRC}$ hot stamped (sample D). The results show that Coefficient of Friction (COF) increased as the hardness of 22MnB5 decreased. Low COF of 0.2114 recorded for sample D with $70 \mathrm{HRC}$ hardness. The COF increased to $0.24,0.29$ and 0.3 when sample $\mathrm{C}$ (60 HRC), sample B (52 HRC) and sample A (45.5 HRC) applied respectively. For pin-on disc test, worn area decreased as the hardness increased. 22MnB5 that prepared with the highest hardness of 70 HRC presented smallest wear area of $700 \mu \mathrm{m}$ x $2400 \mu \mathrm{m}$. It is followed by $800 \mu \mathrm{m}$ x $2400 \mu \mathrm{m}, 1000 \mu \mathrm{m}$ x $2400 \mu \mathrm{m}, 1600 \mu \mathrm{m} \times$ $2800 \mu \mathrm{m}$, when sample C, B and A were scratched. Observation on the worn surface revealed delamination of $22 \mathrm{MnB} 5$ surface in the form of fragmented flaking debris.
\end{abstract}

Keywords: $22 \mathrm{MnB} 5$ boron steel, friction, wear, surface

\subsection{Introduction}

22MnB5 Boron Steel can be categorized as advanced high strength steel (AHSS) that emerged for structural application. The main alloying element of 22MnB5 Boron Steel consisted of $0.22 \mathrm{wt} \% \mathrm{C}, 1.2 \mathrm{wt} \% \mathrm{Mn}$ and $20 \mathrm{ppm}$ B. The addition of $0.22 \mathrm{wt} \% \mathrm{C}$ can be considered as moderate carbon content which make this steel has high formability and less spring back effect when deformed. The addition of $1.2 \mathrm{wt} \% \mathrm{Mn}$ providing hardenability, toughness 
improvement and corrosion resistance with finer grain size. Similar, the addition of boron could improve the yield strength, tensile strength, toughness and hardness of the steel [1-3].

$22 \mathrm{MnB} 5$ Boron Steel is well known on its high strength up to $1500 \mathrm{Mpa}$. On the same time, this material possesses light weight properties due to the thinner part applied in the structural assemblies. In industry, 22MnB5 Boron Steel commonly fabricated by hot stamping process. Hot stamping process involved with heating of 22MnB5 Boron Steel to austenite temperature. The heated 22MnB5 Boron Steel then transferred into the stamping die. Further, the dies will stroke the hot 22MnB5 Boron Steel and simultaneously providing cooling to the stamped part. The microstructure of 22MnB5 Boron Steel changed rapidly from perlite-bainite dominant phase to martensite phase. Consequently, the hardness and strength of hot stamped 22MnB5 Boron Steel elevated superiorly, up to 4 folds improvement [4-5].

Since 22MnB5 Boron Steel possess high strength with light weight capability, this material preferably applied as automotive chassis. The very high yield strength of these steels after heat treatment and hot stamping make them reasonable for anti-intrusion and safety cage parts, including A-pillars, B-pillars, door beams, bumper beams and roof rails. The benefit of high strength and light weight of 22MnB5 Boron Steel enable crashworthiness improvement and fuel save to the automotive vehicles. This offers lower carbon emission that benefitted to the environment and improve safety condition to transportation industries [6-7].

22MnB5 Boron Steel could also potentially applied in abrasive application such as cutting blade, cutting tool, excavator claws or brake disks. Therefore, assessment of friction resistance of this material is important to explore the way of this material failure. Friction test of specific material applies when two materials slide each other in opposite direction. This process represents complex metallurgy interaction at the microscopic level. When materials slide each other, there could possibly heat and force generated consequence from material deformation. Therefore, the behavior of origin material could de changed depended on the sensitivity of that material when exposed to the thermal and mechanical load. On the other hand, the topological alteration of the scratched surface could provide the information of functional behavior and contact condition during materials engagement [8-9].

In the present study, friction behavior of 22MnB5 Boron Steel was assessed by pin-on-disk tests. 4 samples with different hardness were scratched at constant parameters. The Coefficient of Friction (COF) of each sample was compared the relative their mechanical properties on friction resistance. Further, observation of worn surface at the microscopic level was executed by Scanning Electron Microscope.

\subsection{Methodology}

22MnB5 Boron Steel was prepared in the form of metals stamped product as shown in Fig.1. The raw material being parted by hand grinder before cut separately part by part using the laser cutting machine as shown in Fig. 2 . Table 1 shows the parameters used to cut 22MnB5. The thickness of material was set at $2.6 \mathrm{~mm}$ with the diameter of $12 \mathrm{~mm}$. Fig. 3 shows the inserts that have been produced by laser cutting process.

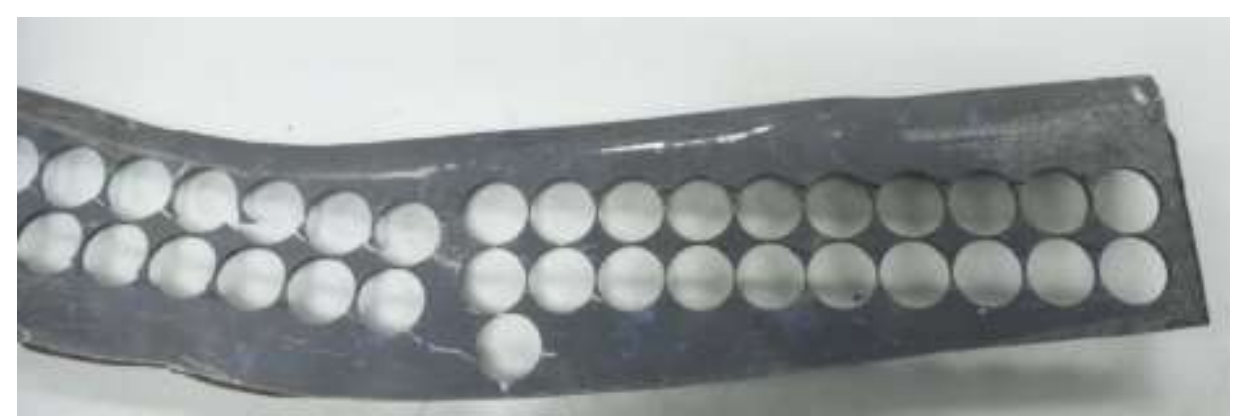

Fig. 1 - Raw 22MnB5 in the form of grinded steel 


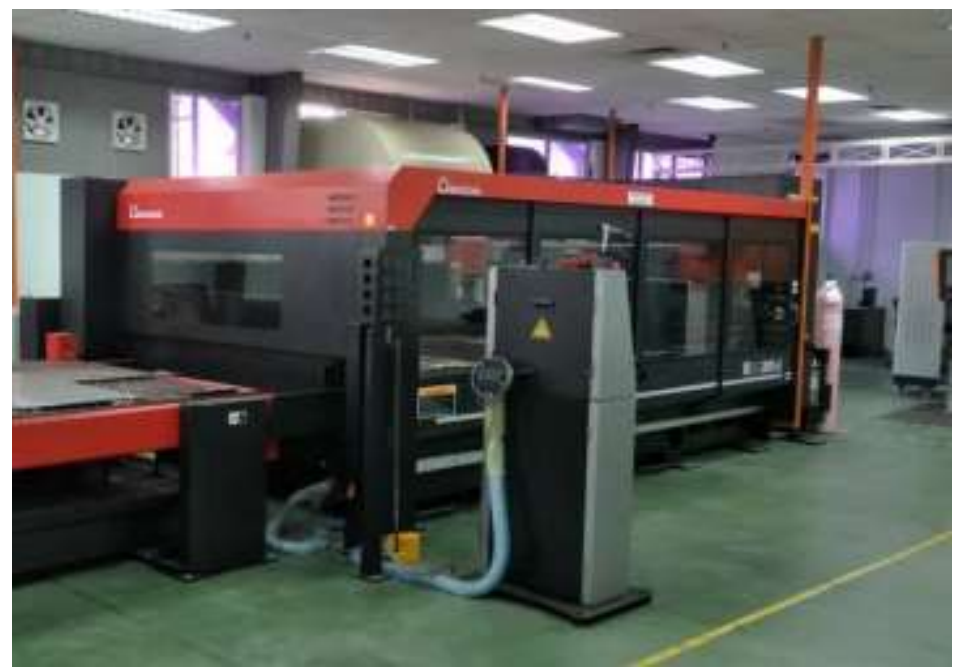

Fig. 2 - Laser cutting machine

Table 1 - Parameter for laser cut feed (F) power (S) freq (P) duty (Q) gas pressure gas kind gas

\begin{tabular}{cccccccc}
\hline Feed (F) & Power (S) & Freq (P) & $\begin{array}{c}\text { Duty } \\
(\mathrm{Q})\end{array}$ & Gas Pressure & Gas Kind & $\begin{array}{c}\text { Tas } \\
\text { Time }\end{array}$ & Nozzle Gap \\
\hline 2800 & 4000 & 1500 & 90 & 0.9 & 5 & 0 & 0.3 \\
\hline
\end{tabular}

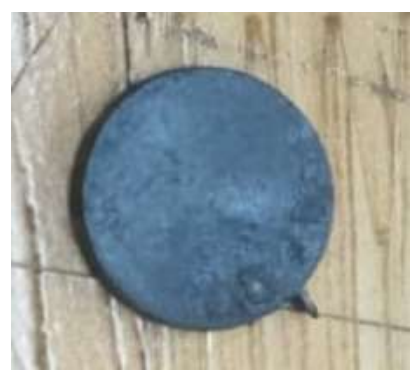

Fig. 3 - 22MnB5 after cut by laser cutting machine

There are 4 samples being investigates for mechanical properties. Table 2 shows the designated condition of each sample.

Table 2 - The designated condition of each sample

\begin{tabular}{cc}
\hline Sample & Condition \\
\hline Sample A & Blank sample \\
\hline Sample B & Blank sample that heats treated by conventional furnace \\
\hline Sample C & Hot stamped sample obtained from industry with 60HRC hardness \\
\hline Sample D & Hot stamped sample obtained from industry with 70HRC hardness \\
\hline
\end{tabular}

Evaluation of Coefficient of Friction (COF) being held by using micro pin on disk tribotester machines, model CM-9109. In pin-on-disc test procedure, a pin is loaded in the form of stainless-steel ball against a flat rotating disc specimen. The movement path of the pin was prescribed by the machine. The parameters selected was $10 \mathrm{~N}$ load, 1800 -s or 30 -minutes time interval, $3 \mathrm{~mm}$ distance and $5 \mathrm{~mm} / \mathrm{s}$ friction velocity. Fig. 4 shows an illustration of the movement of stainless-steel pin friction on the tested 22MnB5 cutting tool. 

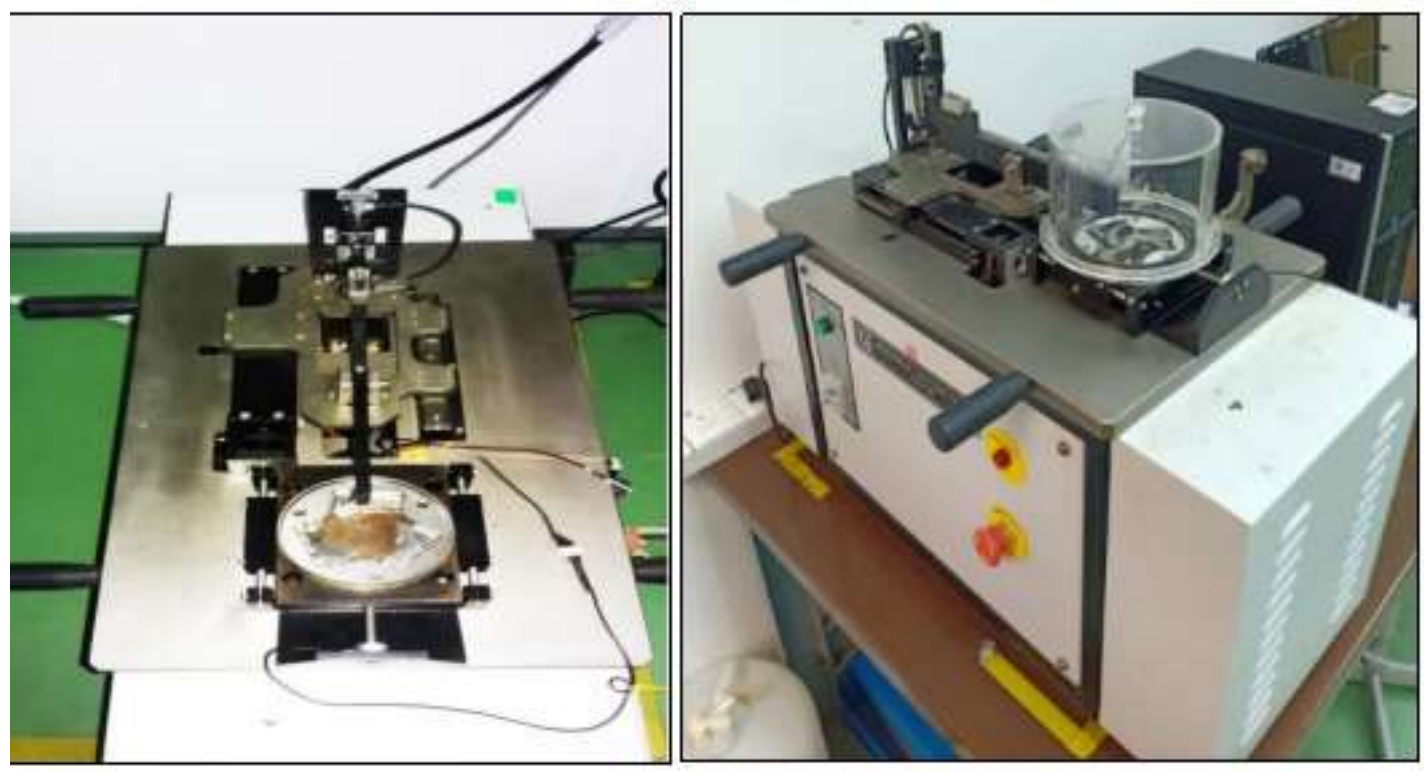

Fig. 4 - Micro pin on disk tribotester

\subsection{Result and Discussion}

Fig. 5 shows the COF graph comparison versus time during pin on disk tests for $1800 \mathrm{~s}$. Figure 4.12 shows average COF value for each sample. For sample A, the initial friction is very high then followed by flat curve. Similar characteristics for Sample B where the friction is high at initial stage and tend to decline slightly as the friction progressed. The oscillations of around the average value are noticeable. This behavior has been attributed to the presence of local roughness variations on the materials surface due to the occurrence of pull-outs fragments because of soft condition of the product [10-11]. Whereas for $\mathrm{C}$, the initial friction is almost half of its value during the initial stage and progress steadily at constant value. In case of $70 \mathrm{Hrc}$, the initial friction started lower and friction increased as the tests progressed. Overall, lowest friction of 0.211 recorded for sample D, whilst higher friction recorded for blank sampel A at 0.3 .

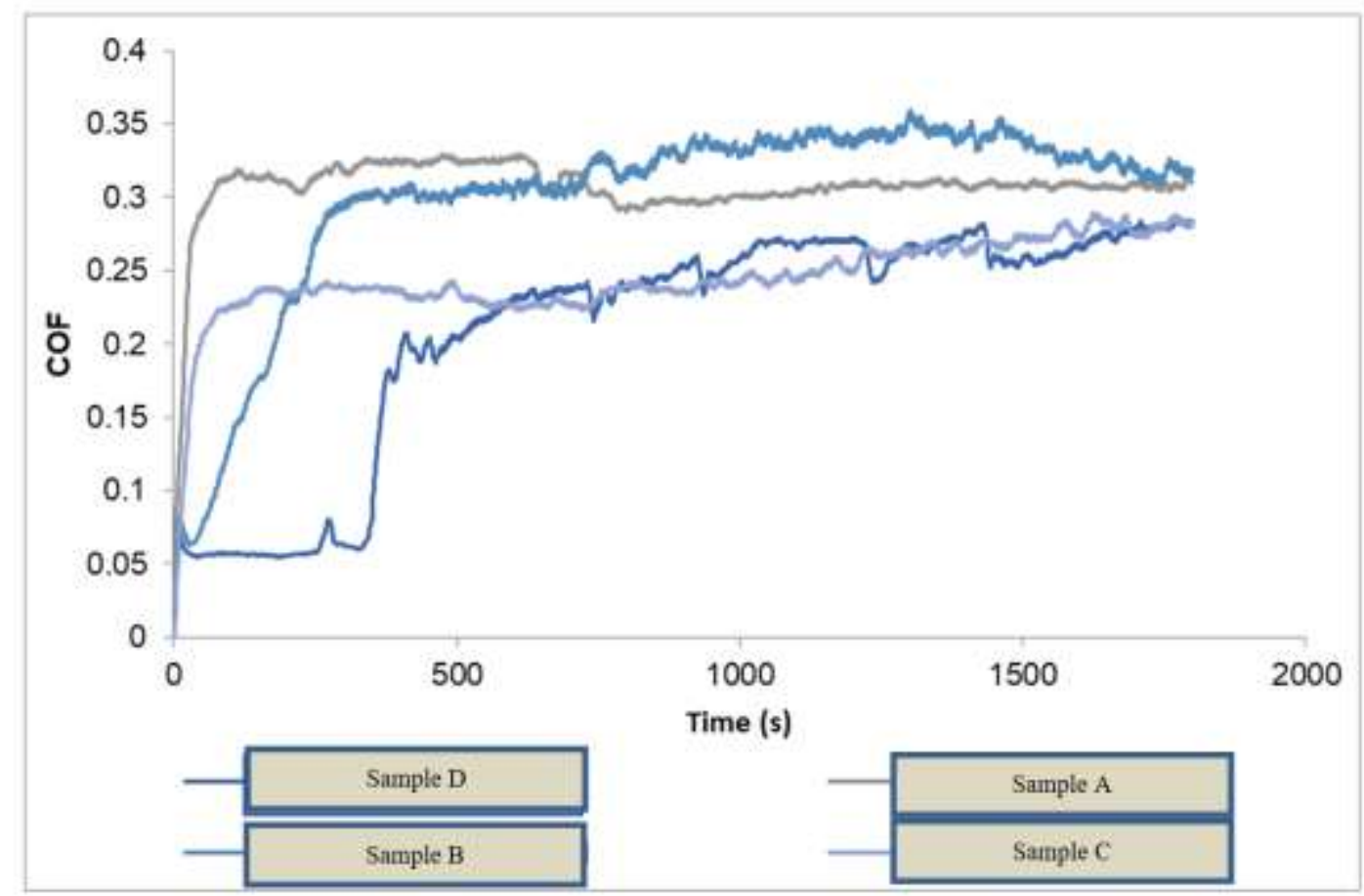

Fig. 5 - Compariosn of friction profiles of each sample during pin on disk tests for $1800 \mathrm{~s}$ 


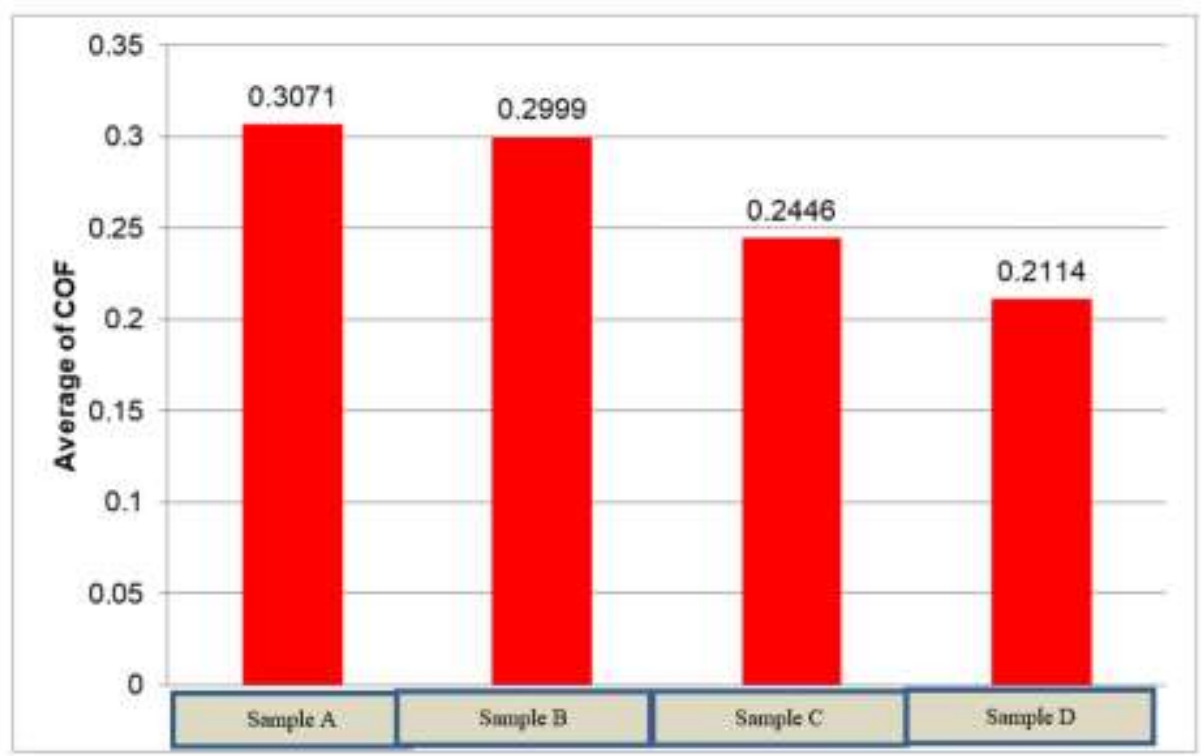

Fig. 6 - Average Coefficient of Friction for tested samples

Fig. 7 shows SEM images for scratched surface after pin-on-disk test at 20X, 100X and 500X magnification. The figure demonstrates the sliding direction which is length $3 \mathrm{~mm}$. It is observed that the width of wear track on boron steel. For sample A, the surface delamination occurred on top of the sample. The size of scratch 1, within the range of $1600 \mu \mathrm{m} \times 2800 \mu \mathrm{m}$ (length $\times$ height). The scratch mark appeared in white colour and it covers the whole scratched area. For sample of B, the scratch area presented smaller region at $1000 \mu \mathrm{m}$ x $2400 \mu \mathrm{m}$ (length $\mathrm{x}$ height). The white scratch area only concentrated at the specific region. The hardened sample shows resistance to pin on this load. In contrast, for sample C, no white scratch mark observed on the worn region. The scratch area presented smaller region at wide round $800 \mu \mathrm{m} \times 2400 \mu \mathrm{m}$ (length $\times$ height). The sample with maximum hardness (sample D) demonstrated ability to resist shear deformation from the pin on disk. The scratch area presented slightly smaller region at $700 \mu \mathrm{m} \mathrm{x}$ $2400 \mu \mathrm{m}$ (length $\mathrm{x}$ height).

The analysis of the worn surface for all samples reveals micro cutting which is a friction mechanism characterized by large mass removal by surface delamination, dominated the wear region. This indicate that the surface of 22MnB5 possess brittle properties where debris lost from the scratched surface in front of the worn area. In practice of machining, such debris could detach out from machining zone to result material lost. Some portion of particles debris could entrap at the cutting zone to further abrade contacted surfaces. For sample A, a lot of scratched flaking and irregular surface appeared due to fragmented deformation imposed by the pin on disc. Similar results presented in Sample B, Figure 4.12(f) where signs of surface delamination, detachment of flaking materials and micro cutting with visible material deformation caused by the pin scratches. For the sample $\mathrm{C}$, the main micro mechanism of surface delamination and material flaking with less area in comparison to the sample A and B. The scratches were less visible consequence from more resistance for deformation because of better hardness on the scratched surface. In Figure 4.12(1), the results presented for the sample D steel indicate micro cutting as the main mechanism but practically limited signs of surface deformation due to the elevated hardness of the material. This suggests lower material removal rates with slightly smaller scratches area [12-13]. 


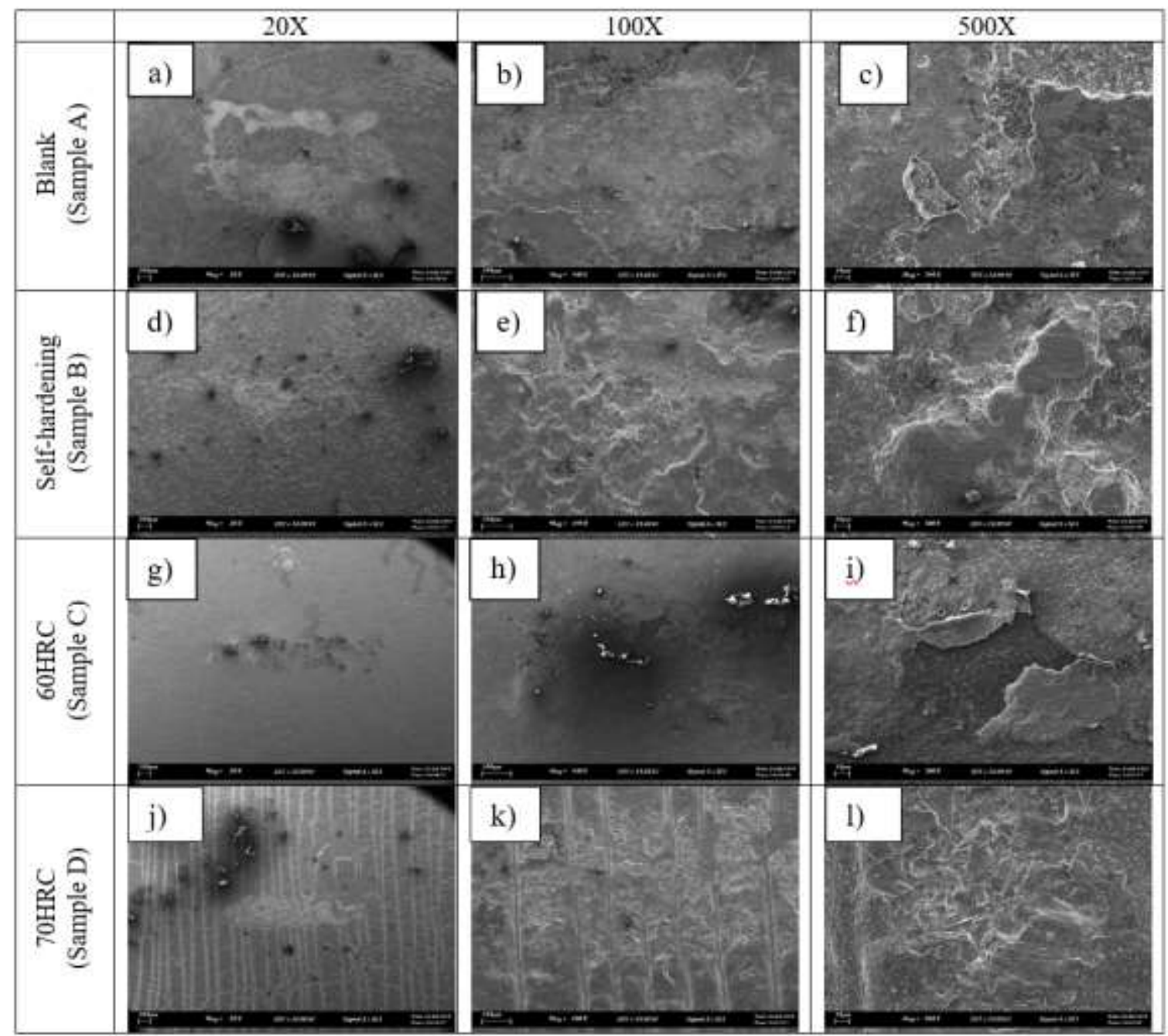

Fig. 7 - SEM images for scratched surface after pin-on-disk tests

\section{Conclusion}

This study intended to characterize wear of 22MnB5 Boron Steel when applied with friction load by using micro pin-on-disk. 4 different samples, consisted of blank (sample A), self-hardening heat treatment (sample B), $60 \mathrm{HRC}$ hot stamped (sample C) and $70 \mathrm{HRC}$ hot stamped (sample D) were examined. Finding from the experimental studies revealed that:

i. Coefficient of Friction decreased as the hardness of 22MnB5 Boron Steel increased. Minimum COF of 0.21 recorded for sample D at the hardness of $70 \mathrm{HRC}$. Maximum COF recorded at 0.3 for sample A at the hardness of 45. 4 HRC.

ii. Worn area decreased as the hardness of 22MnB5 Boron Steel increased.

iii. Wear mechanism on the worn area dominated by the material delamination in the form of fragmented flaking of 22MnB5 debris.

\section{Acknowledgement}

The authors would express their gratitude to Universiti Teknikal Malaysia Melaka (UTeM) for their support through the grant of FRGS/1/2020/FTKMP-CARE/F00438.

\section{References}

[1] Järvinen, H., Honkanen, M., Patnamsetty, M., Järn, S., \& Heinonen, E. (2018). Surface \& Coatings Technology Press hardening of zinc-coated boron steels: Role of steel composition in the development of phase structures within coating and interface regions. Surface \& Coatings Technology, 352, pp.378-391

[2] Gierl, Ch., Mohsin, I.U. \& Danninger, H. (2008) Boron Activated Sintering of PM Steels - Alternative Boron Sources, Powder Metallurgy Progress, 8 (2), 2008, pp.135-141 
[3] Mori, K., Yashima, S., \& Kaido, T. (2018). Direct Springback behaviour and quenchability hot stamping of thick sheets models for capacity optimization in Industry Trade-off between used capacity and operational efficiency Springback behaviour and quenchability in hot stamping of thick. Procedia Manufacturing, 15, pp. 1071-1078

[4] Li, N., Sun, C., Guo, N., Mohamed, M., \& Lin, J. (2016). Journal of Materials Processing Technology Experimental investigation of boron steel at hot stamping conditions. Journal of Materials Processing Technology, 228, pp. 2-10

[5] Golling, S., Frómeta, D., \& Casellas, D. (2018). Influence of microstructure on the fracture toughness of hot stamped boron steel, Materials Science \& Engineering A, 743, pp. 529-539

[6] Lian-fang, H. E., \& Nan, X. (2011). Research on Mechanical Properties of 22MnB5 Steel Quenched in a Steel Die, 16(2), Journal of Shanghai Jiaotong University,16(2), pp. 129-132

[7] Kang, S., Kim, Y., Heo, Y. M., Kim, J. D., \& Won, S. (2017). An Investigation of the trimming of boron nitride steel (22MnB5) An Investigation during of the the trimming of boron process during the die-quenching process. Procedia Engineering, 207, pp.1540-1545

[8] Gracia-escosa, E., García, I., Damborenea, J. J. De, \& Conde, A. (2017). Friction and wear behaviour of tool steels sliding against 22MnB5 steel. Journal of Materials Research and Technology, 6(3), pp. 241-250

[9] Ghiotti, A., Sgarabotto, F. \& Bruschi, S. (2013). A novel approach to wear testing in hot stamping of high strength boron steel sheets. Wear, 302: pp.1319-26

[10]Li, N., Sun, C., Guo, N., Lin, J., \& Takeki, M. (2014). Damage investigation of boron steel at hot stamping conditions. Procedia Engineering, 81, pp.1744-1749

[11]Lu, J., Song, Y., Hua, L., Liu, J., \& Shen, Y. (2017). Influence of thermal deformation conditions on the microstructure and mechanical properties of boron steel. Materials Science \& Engineering A, 701, pp. 328337

[12]Boher, C., Le Roux, S., Penazzi, L. \& Dessain, C. (2012). Experimental investigation of the tribological behavior and wear mechanisms of tool steel grades in hot stamping of a high-strength boron steel. Wear, 294295, pp. 294-295

[13] Mozgovoy, S., Alik, L., Hardell, J., \& Prakash, B. (2019). Material transfer during high temperature sliding of Al-Si coated 22MnB5 steel against PVD coatings with and without aluminium, Wear, 426-427 (Part A), pp. 401-411 